\title{
Commensurability-Based Flood Forecasting in Northeastern China
}

\author{
Zhuoyue Peng ${ }^{1 *}$, Lili Zhang ${ }^{2}$, Junxian Yin ${ }^{2}$, Hao Wang ${ }^{2}$ \\ ${ }^{1}$ College of Environmental Science and Engineering, Donghua University, Shanghai 200051, China \\ ${ }^{2}$ China Institute of Water Resources and Hydropower Research, Beijing 100044, China
}

Received: 31 March 2017

Accepted: 18 May 2017

\begin{abstract}
Northeastern China is one of the largest industrial and agricultural bases in China, but frequent flooding brings huge losses to the people and country. To forecast floods in northeastern China, we used commensurability forecasting techniques and ordered a network structure chart and butterfly structure diagram. The prediction selected extraordinary flooding years that have occurred in the region since 1856, and it used ternary, quinary, and septenary commensurability calculation models for forecasting. It verified the inevitability of flooding in 2013 and showed that northeastern China would be highly prone to flooding in 2017. The specific locations of flooding would be the second Songhua River or Liaohe River. The ordered network structure and butterfly structure diagram are the extension of commensurability, both of which showed perfect symmetry neatly and orderly, and indicated the great possibility of flooding in northeastern China in 2017. Because of spatial distribution in the region, we also picked up four representative sites in the region to subsidiarily forecast the runoff qualitatively. Except for a site that did not have a significant year, the other three sites showed that the runoff in the second Songhua River would be wet in 2017. The idea of this paper is good in the data-starved area and helpful for improving judgment regarding flood trends.
\end{abstract}

Keywords: commensurability, ordered network structure chart, butterfly structure diagram, northeastern China, flood

\section{Introduction}

A flood is one of the most serious natural disasters, and floods typically take place in plain areas that are densely populated, relatively economically developed, and with high degrees of agricultural reclamation. China is one of the most frequent regions for flood disasters. Flood forecasting is not only used as a scientific basis for flood control, drought relief, and reservoir scheduling decisions, but it is also very important in industrial and agricultural

*e-mail: pengzhuoyue123@sina.com production. At present, there are basically two types of longterm runoff forecast methods. The first type is quantitative prediction. The main methods of quantitative prediction are the time series analysis method [1], which is based on mathematical statistics, and regression analysis [2], which is based on physical cause analysis. The other type of runoff forecasting method is qualitative prediction. The most impressive methods include the commensurability prediction method proposed by Weng WenBo [3], and the grey system prediction method proposed by Deng Julong [4].

The status of current disaster prediction is "more single means, less comprehensive methods; more 
historical evaluation, less trend judgment; more academic research, less reduction value" [5]. Weng Wenbo said: "In mathematics, the more complex operations, the more assuming ingredients, the more distortion will be and the farther results apart with the actual situation will be" [3]. If we can contract out of the cycle and symmetric structure from the disaster years, close to its physical mechanism of disaster, we can improve the judgment level of trends about natural disasters. The commensurability method is concise for forecasting the disasters through periodic, vivid, and intuitive symmetry that avoids complicated and unidentifiable traditional mathematical model analysis. Weng Wenbo first used commensurability in natural disaster prediction and founded information forecasting. He successfully predicted that the Yangtze River flood would occur in 1991 and that the California (United States) earthquake would occur in 1992 [3]. This method is a significant theoretical innovation of contemporary natural disaster forecasting that blends the advantage of Chinese and Western science and culture, and has achieved good effect in earthquake, drought, and flood disaster prediction.

Men K.P. used the commensurability principle to predict the flood in the middle and lower reaches of the Yangtze River, and the result showed that there would be floods in 2008, 2029, and 2051 [6]. Hu H. discovered that the occurrences of earthquakes in the Hualian area of Taiwan within the 20th century are commensurable [7]. Li $H$. pointed out that flood-causing rainstorm periods in the Nenjiang River and the Second Songhua River both last 10 years [8]. Jin J used ternary, quaternary, and quinary commensurability methods and a butterfly structure diagram to analyzed the $M s \geq 8.0$ strong earthquakes occurring in Chile, and exhibited an evident symmetry and synchronism in longitudinal and latitudinal directions [9].

It should be noted that not all disasters are cyclical and symmetrical and that not all disaster areas are cyclical and symmetrical; it may be that in one area of one disaster is cyclical and symmetrical only part of the time. Through a large number of empirical analysis in typical regions and distinguished disaster types, areas, and time periods, only in this way can the trend judgment of serious disasters go further. The hydrological phenomenon is cyclically obvious; therefore, the mid- and long-term runoff forecasts based on the commensurability method have been more widely used. This paper used the commensurability method to further explore the trend of flood disasters.

\section{Materials and Methods}

\section{Materials}

\section{Study Area}

Northeastern China, including Liaoning, Jilin, Heilongjiang, and parts of eastern Inner Mongolia, is one of the world's three black soil zones [10]. It is the largest grain base of China and has the most potential for the development of agricultural production areas, and it is also an important industry and energy base. Its area is approximately $800,000 \mathrm{~km}^{2}$, mainly located in the north temperate regions. It is ringed on the east, west, and north by mountains, and the vast Northeast Plain is located in the middle. The river system is various, including the Heilongjiang, Songhua, Ussuri, and Liaohe rivers. Summer rainstorms frequently occur due to the monsoon climate, and this often causes the banks to burst, leading to flooding and serious natural disasters.

In 1998 the Nen River and Songhua River had long, high-intensity rainfall, which was twice more than the same period in an ordinary year, and it triggered a super flood off record. The Jiangqiao hydrological station in the Nen River measured maximum peak flow $\left(26,400 \mathrm{~m}^{3} / \mathrm{s}\right)$ and the flood return period was 480 years. The Harbin Hydrology Station in the Songhua River measured peak flow $\left(16,600 \mathrm{~m}^{3} / \mathrm{s}\right)$ and the flood return period was approximately 100 years. In 2013 the water level soared again in northeastern China, and there was a basin-wide flood in the Heilongjiang River, and the return period of downstream in the Heilingjiang was more than 100 years (Bulletin of Flood and Drought Disaster in China, 2014; www.mwr.gov.cn/zwzc/hygb/zgshzhgb). Based on the important industrial and agricultural status and the flood-prone nature of the region, flood forecasting is even more important.

Because the spatial distribution of summer precipitation in northeastern China is more in the south and less in the northwest [11], when choosing a representative point we chose reservoirs in the east or south. Fengman Reservoir is located upstream, $24 \mathrm{~km}$ from Jilin, and the control drainage area is $42,500 \mathrm{~km}^{2}$, which accounting for $55 \%$ of the second Songhua River. The Fengman Reservoir is a large reservoir mainly used for generating electrical power, flood control, irrigation, water supply, and shipping. Fengman Dam, constructed in 1937, was reconstructed on 29 October 2012. Baishan Reservoir is located in the upstream, $200 \mathrm{~km}$ from Fengman Reservoir, with a control drainage area of $19,000 \mathrm{~km}^{2}$. It has given priority to power generation, and also affects flood control, navigation, and fish culture. The plant started production at the end of 1983. The total reservoir capacity of Baishan and Fengman is $1.69 \times 10^{10} \mathrm{~m}^{3}$, and their capacity accounts for $53.6 \%$ of total reservoir capacity $\left(3.15 \times 10^{10} \mathrm{~m}^{3}\right)$ in the Songhua River, making them both the most important flood control projects in the second Songhua River [12]. Yunfeng Reservoir is located in the middle reaches of the Yalu River and upstream, $50 \mathrm{~km}$ from Ji'an. Reservoir catchment area is more than $23,936 \mathrm{~km}^{2}$ and its total reservoir capacity is $3.90 \times 10^{9} \mathrm{~m}^{3}$. This reservoir is a hybrid development, which gives priority to power generation as well as comprehensive utilization benefits, and it began operation in 1965 [13]. The two plants of the Jingpo River Station are located upstream of Mudanjiang, $100 \mathrm{~km}$ from southwestern Mudanjiang. The control area is $11,800 \mathrm{~km}^{2}$ and it occupies $31 \%$ of the Mudanjiang River basin. It is a large reservoir used to generate electrical power and for 


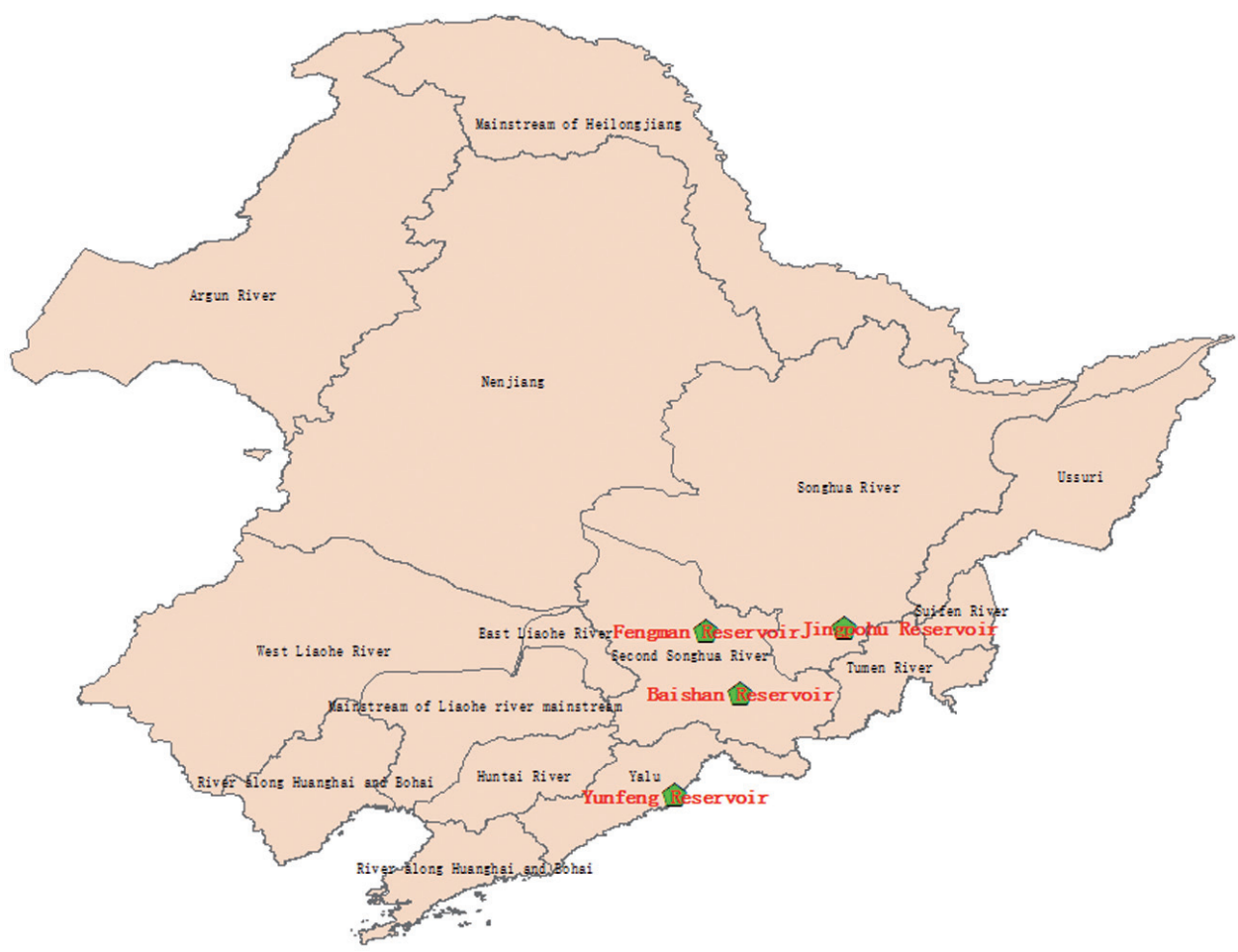

Fig. 1. Basin map and reservoir site map of northeastern China.

flood control. The old plant was constructed in 1942 and a new plant began generating electricity in 1978 [14].

\section{Research Object and Data Source}

\section{Divided Basis of Research Object}

Flood grades are classified based on the hydrological forecasting standard (GB/T22482-2008). According to flood frequency, floods are divided into four levels in Table 1. Flood frequency is defined with water level or discharge. The flood return period beyond 50 years, that is the value of flood frequency beyond $2 \%$, is called an "extraordinary flood."

According to the departure from the mean value (the numerator is the number of runoff in July to September minus the year's average value, and the denominator is the year's average rainfall, then the quotient is the so-called "departure from the mean value") floods are divided into the five levels shown in Table 2.

\section{Data Source}

We chose 15 extraordinary flood events (the value of flood frequency beyond $2 \%$ ) in northeastern China as the research subjects to build the commensurability prediction model. Twelve of these floods were recorded in China Historical Great Flood (1988), and the other floods occurred in 1995, 1998, and 2010. The history was not detailed; therefore, the date was just kept to the month. The majority of floods occurred in the summer; therefore, years without mouth or data were selected in the commensurability prediction program.

\section{Methods}

\section{Commensurability}

\section{Definition of Commensurability}

Commensurability is an order of nature that expresses a certain law stating that various elements of the system can work together and reflect the occurrence rule of special events (small probability events) in nature. We can extract the non-accidental signals from a special series of commensurable numbers to predict flood tendency, which means we use special events to forecast special events.

"Commensurability" was first proposed in the study of astronomy, when Laplace found Jupiter's moons (Io, Europa, Ganymede) and their average distance $\left(\mathrm{x}_{1}, \mathrm{x}_{2}, \mathrm{x}_{3}\right)$ to the primary component obeys the commensurability type below:

Table 1. Flood classifications.

\begin{tabular}{|c|c|c|c|c|}
\hline $\begin{array}{c}\text { Flood } \\
\text { Frequency }(\mathrm{P})\end{array}$ & $\mathrm{P}<20 \%$ & $20 \% \leq \mathrm{P}<5 \%$ & $5 \% \leq \mathrm{P}<2 \%$ & $\mathrm{P} \geq 2 \%$ \\
\hline Classifications & Small Flood & Middle Flood & Big Flood & Extraordinary Flood \\
\hline
\end{tabular}


Table 2. Annual runoff classification table.

\begin{tabular}{|c|c|c|c|c|c|}
\hline Classifications & Dry year & Slightly dry year & Flat year & Slightly wet year & Wet year \\
\hline Departures(D) & $\mathrm{D}<-20 \%$ & $-20 \%\langle\langle\mathrm{D}<-10 \%$ & $-10 \%\langle\langle\mathrm{D}\langle\langle 10 \%$ & $10 \%<\mathrm{D}\langle\langle 20 \%$ & $\mathrm{D}>20 \%$ \\
\hline
\end{tabular}

$$
2 x_{3}-2 x_{2}=x_{2}-x_{1}
$$

The academician Weng predicted the occurrence time of natural disasters based on setting the commensurability formula with commensurability theory. The formula is usually expressed as:

$$
\mathrm{X}_{\mathrm{i}+1}=\sum_{\mathrm{j}=1}^{\mathrm{l}} \mathrm{I}_{\mathrm{j}} \mathrm{X}_{\mathrm{j}}
$$

$\ldots$ where $\mathrm{j} \in\{\mathrm{i}\}, \mathrm{i}=1,2, \ldots, \mathrm{n}$, (n is a positive integer), and $I_{j}$ is an integer.

To prove a non-accidental type of commensurability formula, there must be two or more formulas to verify:

$$
\left\{\begin{array}{c}
\mathrm{X}_{\mathrm{i}+1,1}=\sum_{\mathrm{j} 1=1}^{\mathrm{l} 1} \mathrm{I}_{\mathrm{j} 1} \mathrm{X}_{\mathrm{j} 1} \\
\mathrm{X}_{\mathrm{i}+1,2}=\sum_{\mathrm{j} 2=1}^{\mathrm{l} 2} \mathrm{I}_{\mathrm{j} 2} \mathrm{X}_{\mathrm{j} 2} \\
\vdots \\
\mathrm{X}_{\mathrm{i}+1, \mathrm{~m}}=\sum_{\mathrm{jm}=1}^{\operatorname{lm} \mathrm{I}_{\mathrm{jm}} \mathrm{X}_{\mathrm{jm}}}
\end{array}\right.
$$

Arrange the above values in a monotonically increasing collection:

$$
\left\{X_{(i+1), 1}, X_{(i+1), 2}, \cdots, X_{(i+1), m}\right\}
$$

Restrictions:

$$
\left|X_{(i+1), m}-X_{(i+1), 1}\right| \leq \varepsilon
$$

$\varepsilon$ is the critical value that determines the feasibility of the model. We determined the value of in the practical work according to specific needs. Generally, $\varepsilon= \pm 1$ is required in the prediction of hydrological disasters [15]. The sample is completely commensurable when $\varepsilon=0$. If $\varepsilon>0$, the $\Delta X$ is the commensurability ash cycle between $[-\varepsilon, \varepsilon]$. If the commensurability formulas can be more than one formula, the formula may be not accidental. The larger the $m$ (the number of commensurability formulas) and the smaller the $\varepsilon$, the higher the forecast accuracy.

The three models for the extrapolation forecasts are as follows:

\begin{tabular}{|c|c|c|c|}
\hline $\begin{array}{l}\text { Serial } \\
\text { Number }\end{array}$ & $\begin{array}{c}\text { Prediction } \\
\text { year }\end{array}$ & Illustration & Degree of hazard \\
\hline 1 & $1856 / 8$ & In the middle of Jilin & Peak flow reached $13,800 \mathrm{~m}^{3} / \mathrm{s}$ in Songhua Reach in the Second Songhua River \\
\hline 2 & $1888 / 8 / 14$ & East of Liaoning & Peak flow reached $11,900 \mathrm{~m}^{3} / \mathrm{s}$ in Shenyang Reach at Liaohe river basin \\
\hline 3 & $1909 / 7 / 24$ & $\begin{array}{l}\text { In the middle of the Second } \\
\text { Songhua River }\end{array}$ & Peak flow reached $12,900 \mathrm{~m}^{3} / \mathrm{s}$ in Jilin Reach at Second Songhua River \\
\hline 4 & $1911 / 8 / 12$ & $\begin{array}{l}\text { Hulan River and Tangwang } \\
\text { River in Songhua River }\end{array}$ & Peak flow reached $11,600 \mathrm{~m}^{3} / \mathrm{s}$ in Hongshilazi Reach at Second Songhua River \\
\hline 5 & $1930 / 8 / 4$ & West of Liaoning & Peak flow reached $11,700 \mathrm{~m}^{3} / \mathrm{s}$ in Jinzhou Reach at Liao River \\
\hline 6 & $1932 / 8 / 6$ & Songhua River & Peak flow reached $17,800 \mathrm{~m}^{3} / \mathrm{s}$ in Tonghe Reach at Songhua River \\
\hline 7 & $1953 / 8 / 10$ & Liaohe and Songhua Rivers & Peak flow reached 3,940 m³ $/ \mathrm{s}$ in Bei'anhe Reach at Nen River \\
\hline 8 & $1957 / 9 / 9$ & Songhua River & Peak flow reached $17,800 \mathrm{~m}^{3} / \mathrm{s}$ in Tonghe Reach at Songhua River \\
\hline 9 & $1960 / 8 / 4$ & East of Liaohe & Peak flow reached $14,300 \mathrm{~m}^{3} / \mathrm{s}$ in Benxi Reach at Taizi River \\
\hline 10 & $1962 / 7 / 26$ & West of Liaohe & Peak flow reached $12,200 \mathrm{~m}^{3} / \mathrm{s}$ in Xiaoheyan Reach at Liao River \\
\hline 11 & $1981 / 7 / 28$ & Liaodong Peninsula & Peak flow reached $5,460 \mathrm{~m}^{3} / \mathrm{s}$ in Xiaosongjiatun Reach at Yellow Sea \\
\hline 12 & $1985 / 7 / 20$ & Liaohe & Peak flow reached $27,400 \mathrm{~m}^{3} / \mathrm{s}$ in Haicheng Reach at Taizi River \\
\hline 13 & $1995 / 7 / 30$ & $\begin{array}{l}\text { Liaohe and the second } \\
\text { Songhua Rivers }\end{array}$ & Peak flow reached $10,700 \mathrm{~m}^{3} / \mathrm{s}$ in Dahuofang Reservoir Reach at Hun River \\
\hline 14 & $1998 / 8 / 14$ & Songhua River & Peak flow reached $26,400 \mathrm{~m}^{3} / \mathrm{s}$ in Jiangqiao Reach at Nen River \\
\hline 15 & $2010 / 8 / 18$ & Second Songhua River & Peak flow reached $5,230 \mathrm{~m}^{3} / \mathrm{s}$ in Harbin station at mainstream of Songhua River \\
\hline
\end{tabular}

The ternary commensurability equation:

$$
\mathrm{X}_{\mathrm{a}}+\mathrm{X}_{\mathrm{b}}-\mathrm{X}_{\mathrm{c}}=\mathrm{X}_{\mathrm{u}(\mathrm{a}, \mathrm{b}, \mathrm{c})}
$$

Table 3. Sample years of floods in northeastern China. 
The quinary commensurability equation:

$$
\mathrm{X}_{\mathrm{a}}+\mathrm{X}_{\mathrm{b}}+\mathrm{X}_{\mathrm{c}}-\mathrm{X}_{\mathrm{d}}-\mathrm{X}_{\mathrm{e}}=\mathrm{X}_{\mathrm{v}(\mathrm{a}, \mathrm{b}, \mathrm{c}, \mathrm{d}, \mathrm{e})}
$$

The septenary commensurability equation:

$\mathrm{X}_{\mathrm{a}}+\mathrm{X}_{\mathrm{b}}+\mathrm{X}_{\mathrm{c}}+\mathrm{X}_{\mathrm{d}}-\mathrm{X}_{\mathrm{e}}-\mathrm{X}_{\mathrm{f}}-\mathrm{X}_{\mathrm{g}}=\mathrm{X}_{\mathrm{w}(\mathrm{a}, \mathrm{b}, \mathrm{c}, \mathrm{d}, \mathrm{e}, \mathrm{f}, \mathrm{g})}$

$\ldots$ where a, b, c, d, e, f, g $=1,2 \cdots, \mathrm{n}$; and $\mathrm{u}, \mathrm{v}, \mathrm{w}=1,2, \cdots \mathrm{m}$. $\mathrm{n}$ and $\mathrm{m}$ are positive integers.

This paper adopted ternary, quinary, and septenary commensurability prediction models to forecast floods in northeastern China. The first preference was given to the value of ternary commensurability formula. When the values in the ternary commensurability formula are the same, you can refer to quinary and septenary commensurability formulas. Under normal circumstances we prefer the value of ternary commensurability formula results over the quinary commensurability formula, and prefer the value of quinary commensurability formula results over the septenary commensurability formula.

\section{Commensurability Inspection}

Weng Wenbo divided the objective existence into two categories: the normal states subset and the abnormal states subset. The normal states subset includes the general, frequent events, and the main elements are statistics, such as the mathematical expectation, equation, and mean. The abnormal states subset includes unusual, special events, and the data are processed based on the characteristics of each element.

To determine if the original time series has a non-uniform distribution, not accidental, and it has a strong value to extract information, this paper assumed that the original time sequence was an even distribution. If it had a low confidence level by using a statistical test, we believed that the sequence might be a uniform distribution. On the contrary, if we rejected the hypothesis of an even distribution, we could establish their own relationship between years to forecast disaster trends.

$\mathrm{F}(\mathrm{x})$ is a sample sequence and $\left(\mathrm{X}_{1}, \mathrm{X}_{2}, \cdots, \mathrm{X}_{\mathrm{n}}\right)$ is a sample from the population. We assumed that the sample obeyed the uniform distribution function $\mathrm{F}_{0}(\mathrm{x})$ in the interval $[a, b]$. We examined the overall distribution to determine whether it had a uniform distribution, which meant we tested whether $\mathrm{H}_{0}$ : $\mathrm{F}(\mathrm{x})=\mathrm{F}_{0}(\mathrm{x})$ was true. This study applied the ternary commensurability chi-square test method to determine the parameters of uniform distribution. The ternary commensurability formula is $X_{m}=X_{k}+X_{s}-X_{n}$, $\mathrm{m}=\mathrm{k}+\mathrm{l}-\mathrm{n}$ in an evenly distributed case.

Actual frequency $\mathrm{X}$ of ternary extrapolation formula:

$$
\mathrm{X}=\sum_{\mathrm{i}=1}^{\mathrm{S}} \Delta \mathrm{X}_{\mathrm{i}}
$$

...where $\mathrm{s}$ is the number of the ternary commensurability formula and $\Delta \mathrm{X}$ is the frequency of each partial interval when extrapolated:

$$
\Delta \mathrm{X}= \begin{cases}2, & \mathrm{k} \neq \mathrm{s} \\ 1, \mathrm{k}=\mathrm{s}\end{cases}
$$

Theory frequency $\lambda_{\mathrm{x}}$ of uniformly distributed:

$$
\lambda_{\mathrm{x}}=\mathrm{Np}_{\mathrm{i}}
$$

$\mathrm{N}$ is the sum of frequency, $\mathrm{N}=\sum_{\mathrm{i}=1}^{\mathrm{n}} \mathrm{X}_{\mathrm{i}}$, that is, the sample size. $p_{i}$ is the theoretical probability of each sample, typically $1 / \mathrm{n}$.

2) Degrees of freedom in an even distribution:

$$
f=r-m-1
$$

$\ldots$ where $r$ is year span, $r=\max \{(n-k),(n-s)\}$. If $k=s$, then $\mathrm{m}=1$, instead of 2 .

3) Use of K. Pearson-Fisher theorem

If $\mathrm{H}_{0}$ is established, the theoretical frequency and actual frequency should be almost the same. Therefore, we configured the statistics:

$$
\chi^{2}=\sum \frac{\left(\mathrm{X}-\mathrm{Np}_{\mathrm{i}}\right)^{2}}{\mathrm{~Np}_{\mathrm{i}}}
$$

According to K. Pearson-Fisher theorem, the distribution obeys $\chi^{2} \sim \chi^{2}(\mathrm{r}-\mathrm{m}-1)$. At the significance level $\alpha$, if $\chi^{2} \geq \chi_{1-\alpha}^{2}(r-m-1)$ then refuse $\mathrm{H}_{0}$; if $\chi^{2} \leq \chi_{1-\alpha}^{2}(\mathrm{r}-\mathrm{m}-1)$, then accept $\mathrm{H}_{0}$.

\section{Commensurability Unit and Ordered Network Structure Chart}

Commensurability can be view as an expansion of periodicity, and we can call a time scale the "commensurability unit," where there will be a disaster when passing a unit. The same scale occurs repeatedly, which would forecast the disaster relatively simply and practically. The present study showed that the main reasons for the hydrological cycle phenomena are the movement of celestial objects, Earth's rotation and revolution, and solar activity.

The network can extend unlimitedly, and it has been widely used in various subject areas. An ordered network structure chart is a network of visual manifestations that combine cyclicity with the order. The ordered network structure is an ordered collection of nodes and their ligatures. The nodes are sample points, and the ligatures are time scales. When building a chart, we were only concerned with the orderliness about the length of the ligature (time scale) between nodes. We did not care about the position of the nodes or whether the ligatures were straight or intersected, etc., which may be twodimensional or multidimensional. It may also be a series 
Table 4. Reference standard of butterfly structure's probability calculation.

\begin{tabular}{|c|c|c|}
\hline Data & Groups of every unit & Unit \\
\hline $\mathrm{N} \leq 5$ & groups $\geq 2$ & $\geq 1$ \\
\hline $6 \leq \mathrm{N} \leq 10$ & groups $\geq 3$ & $\geq 2$ \\
\hline $11 \leq \mathrm{N} \leq 15$ & groups $\geq 4$ & $\geq 3$ \\
\hline $16 \leq \mathrm{N} \leq 20$ & groups $\geq 5$ & $3 \sim 4$ \\
\hline $\mathrm{N} \geq 20$ & groups $\geq 6$ & $\geq 4$ \\
\hline
\end{tabular}

of diagrams to describe the network to ensure correlation between all of the samples, and individual samples can be reused.

\section{Butterfly Structure Diagram}

The butterfly structure diagram is a method established at equal time scale, connected with a curved profile and shaped like a butterfly to react with time symmetry [16]. In the sample, the random probability of the butterfly structure is calculated using, where $T$ is the probability of occurrence in the predicted year, $\mathrm{n}$ is the number of total disaster events used for prediction, and $\mathrm{m}$ is the number of disaster events involved in the actual prediction. To improve the judgement level of the disaster trend, generally we determine the lower limit number of butterfly structure according to the amount of year data in the time sequence.

\section{Flood Forecasting Techniques Combined Points with Area}

The ability to forecast specific location elements of extraordinary floods is the direction of information forecast development and the key to prevention or mitigation. Based on historical materials regarding the hydrology in the basin, the flood years for the Nenjiang River are 1794, 1886, 1908, 1929, 1932, 1953, 1957, 1969, and 1998, while those for the Songhua River are 1856, 1896, 1909, 1923, 1951, 1953, 1957, 1960, 1991, 1995, and 2010 [8]. With the exception of 1953 and 1957 according to these data, floods in the two places have not occurred at the same time. This phenomenon can be used to reduce flood control pressures, but it also leads to confusion in forecasting flood location and determining which river will flood. Scholars generally just stay in forecast occurrence time as there is little for detailed location prediction.
We combined points (four reservoirs) with area (northeastern China), which not only improves prediction accuracy in entire areas, but also can determine the point location of the floods. The area forecast selected drainage basin floods as samples. We checked the commensurability of the samples first and then used the commensurability formula, commensurability unit, and ordered network structure chart with the butterfly structure diagram to predict the floods in the region. The point forecast would be auxiliary, and picked up the flow series of a particular site as samples to predict the runoff of the watershed. This method ensured the rationality and completeness of the prediction from time and space.

\section{Results and Discussion}

\section{Commensurability Formula}

First, we tested the non-accidental of the commensurability formula with the uniform distribution hypothesis testing method. As shown in Table 6, X was the actual frequency and the average probability value calculated by the number of years involved in the ternary commensurability formula divided by the total number of years, such as 1856 , the years involved in the ternary commensurability formula were 1888, 1909, 1911, 1930, $1932,1953,1957,1962,1985$, and 2010 for a total of 10 , and the total number of sample years is 15 , so the probability value is $67 \%$. Shown in Table 6 , the average value of $\mathrm{X}$ was 16 , and the average probability value was $69.9 \%$.

We obtained $\chi^{2}=43.74$ from Table 7 , then we checked the $\chi^{2}$ distribution table to obtain $\left.\chi_{1-\alpha}^{2}(r-m-1)=\chi_{1-0.005}^{2}(14-2-1)\right)=26.8$. Because $\chi^{2}=43.74>26.8$, we had a $99.5 \%$ probability to reject $\mathrm{H}_{0}$, which meant the sequence was not uniformly distributed. The results showed that the ternary commensurability equation was not accidental. Therefore, we can try it for disaster prediction.

The results of ternary, quinary, and septenary commensurability in the commensurability prediction model are shown in Table 8.

After the mutual authentication of the ternary, quinary, and septenary commensurability calculations, 2013 ranked first in the ternary, quinary, and septenary commensurability calculations. The ternary commensurability formula is shown in Table 9, where we found that most locations of flooding join in the ternary commensurability formula of 2013 were the second Songhua River and Liaohe River,

Table 5. Correspondence between random probability of butterfly structure and capable degree of prediction.

\begin{tabular}{|c|c|c|c|c|}
\hline Random Probability $(\mathrm{T})$ & $\mathrm{T}<1 \%$ & $1 \% \leq \mathrm{T}<10 \%$ & $10 \% \leq \mathrm{T}<33 \%$ & $33 \% \leq \mathrm{T}<66 \%$ \\
\hline Capable Degree & very unlikely & most unlikely & unlikely & not entirely possible \\
\hline Random Probability $(\mathrm{T})$ & $66 \% \leq \mathrm{T}<90 \%$ & $90 \% \leq \mathrm{T}<99 \%$ & $\mathrm{~T} \geq 99 \%$ & \\
\hline Capable Degree & possible & basic may & may well & \\
\hline
\end{tabular}


Table 6. Ternary commensurability formula, frequency, and probability of every year.

\begin{tabular}{|c|c|c|c|c|c|}
\hline Year & \multicolumn{3}{|c|}{ Ternary commensurability formula } & Frequency $\mathrm{x}$ & Probability $\%$ \\
\hline \multirow{3}{*}{1856} & $1888+1930-1962$ & $1888+1953-1985$ & $1909+1909-1962$ & \multirow{3}{*}{13} & \multirow{3}{*}{67} \\
\hline & $1909+1932-1985$ & $1911+1930-1985$ & $1930+1888-1962$ & & \\
\hline & $1957+1909-2010$ & & & & \\
\hline \multirow{3}{*}{1888} & $1856+1985-1953$ & $1909+1909-1930$ & $1909+1911-1932$ & \multirow{3}{*}{17} & \multirow{3}{*}{73} \\
\hline & $1909+1932-1953$ & 1909+1960-1981 & $1911+1962-1985$ & & \\
\hline & $1930+1911-1953$ & $1930+1953-1995$ & $1962+1856-1930$ & & \\
\hline \multirow{5}{*}{1909} & $1856+1962-1909$ & $1888+1930-1909$ & $1911+1930-1932$ & \multirow{5}{*}{26} & \multirow{5}{*}{87} \\
\hline & $1856+1985-1932$ & $1888+1932-1911$ & $1911+1960-1962$ & & \\
\hline & $1856+2010-1957$ & $1888+1981-1960$ & $1930+1960-1981$ & & \\
\hline & $1932+1930-1953$ & $1962+1932-1985$ & $1962+1957-2010$ & & \\
\hline & $1953+1888-1932$ & & & & \\
\hline \multirow{4}{*}{1911} & $1856+1985-1930$ & $1909+1932-1930$ & $1953+1888-1930$ & \multirow{4}{*}{18} & \multirow{4}{*}{73} \\
\hline & $1888+1932-1909$ & $1888+1985-1962$ & $1909+1962-1960$ & & \\
\hline & $1930+1962-1981$ & $1932+1960-1981$ & $1932+1932-1953$ & & \\
\hline & $1953+1953-1995$ & & & & \\
\hline \multirow{4}{*}{1930} & $1856+1962-1888$ & $1909+1932-1911$ & $1911+1981-1962$ & \multirow{4}{*}{24} & \multirow{4}{*}{73} \\
\hline & $1909+1909-1888$ & $1888+1995-1953$ & $1932+1960-1962$ & & \\
\hline & $1856+1985-1911$ & $1909+1953-1932$ & $1953+1962-1985$ & & \\
\hline & $1888+1953-1911$ & $1909+1981-1960$ & $1985+1930-1985$ & & \\
\hline \multirow{4}{*}{1932} & $1856+1985-1909$ & $1909+1985-1962$ & $1930+1962-1960$ & \multirow{4}{*}{24} & \multirow{4}{*}{87} \\
\hline & $1888+1953-1909$ & $1911+1930-1909$ & $1953+1960-1981$ & & \\
\hline & $1909+1911-1888$ & $1911+1953-1932$ & $1957+1960-1985$ & & \\
\hline & $1909+1953-1930$ & $1911+1981-1960$ & $1957+1985-2010$ & & \\
\hline \multirow{4}{*}{1953} & $1888+1995-1930$ & $1930+1985-1962$ & $1981+1932-1960$ & \multirow{4}{*}{19} & \multirow{4}{*}{80} \\
\hline & $1909+1932-1888$ & $1932+1932-1911$ & $1985+1856-1888$ & & \\
\hline & $1930+1911-1888$ & $1957+1981-1985$ & $1995+1911-1953$ & & \\
\hline & $1930+1932-1909$ & & & & \\
\hline \multirow{3}{*}{1957} & $1856+2010-1909$ & $1932+2010-1985$ & $1953+1985-1981$ & & \\
\hline & $1909+2010-1962$ & $1953+1957-1953$ & $1960+1995-1998$ & 14 & 80 \\
\hline & $1932+1985-1960$ & & & & \\
\hline & $1957+1998-1995$ & $1981+1888-1909$ & $1981+1932-1953$ & & \\
\hline 1960 & $1962+1909-1911$ & $1981+1909-1930$ & $1985+1932-1957$ & 17 & 80 \\
\hline & $1962+1930-1932$ & $1981+1911-1932$ & $1985+1985-2010$ & & \\
\hline & $1888+1930-1856$ & $1909+1985-1932$ & $1911+1981-1930$ & & \\
\hline 1962 & $1888+1985-1911$ & $1909+2010-1957$ & $1930+1985-1953$ & 17 & 80 \\
\hline & $1909+1909-1856$ & $1911+1960-1909$ & $1932+1960-1930$ & & \\
\hline 1981 & $1909+1960-1888$ & $1932+1960-1911$ & $1953+1960-1932$ & 12 & 67 \\
\hline 1981 & $1930+1960-1909$ & $1930+1962-1911$ & $1953+1985-1957$ & 12 & $6 /$ \\
\hline & $1888+1953-1856$ & $1932+1962-1909$ & $1957+1960-1932$ & & \\
\hline & $1909+1932-1856$ & $1932+2010-1957$ & $1957+1981-1953$ & & \\
\hline 1985 & $1911+1930-1856$ & $1953+1962-1930$ & $1960+2010-1985$ & 20 & 87 \\
\hline & $1911+1962-1888$ & & & & \\
\hline 1995 & $1930+1953-1888$ & $1953+1953-1911$ & $1957+1998-1960$ & 5 & 47 \\
\hline 1998 & $1960+1995-1957$ & & & 2 & 20 \\
\hline & $1957+1909-1856$ & $1957+1985-1932$ & $1985+1985-1960$ & & \\
\hline 2010 & $1957+1962-1909$ & & & 7 & 47 \\
\hline
\end{tabular}


Table 7. Theoretical frequency and each parameter value of chisquare test with each year.

\begin{tabular}{|c|c|c|c|c|}
\hline Year & $\begin{array}{c}\text { Actual } \\
\text { frequency } \\
(\mathrm{X})\end{array}$ & $\begin{array}{c}\text { Theoretical } \\
\text { frequency } \\
\text { (Npi) }\end{array}$ & X-Npi & $\begin{array}{c}\text { (X-Npi) } 2 / ~ \\
\text { Npi }\end{array}$ \\
\hline 1856 & 13 & 15.67 & -2.67 & 0.45 \\
\hline 1888 & 17 & 15.67 & 1.33 & 0.11 \\
\hline 1909 & 26 & 15.67 & 10.33 & 6.81 \\
\hline 1911 & 18 & 15.67 & 2.33 & 0.35 \\
\hline 1930 & 24 & 15.67 & 8.33 & 4.43 \\
\hline 1932 & 24 & 15.67 & 8.33 & 4.43 \\
\hline 1953 & 19 & 15.67 & 3.33 & 0.71 \\
\hline 1957 & 14 & 15.67 & -1.67 & 0.18 \\
\hline 1960 & 17 & 15.67 & 1.33 & 0.11 \\
\hline 1962 & 17 & 15.67 & 1.33 & 0.11 \\
\hline 1981 & 12 & 15.67 & -3.67 & 0.86 \\
\hline 1985 & 20 & 15.67 & 4.33 & 1.2 \\
\hline 1995 & 5 & 15.67 & -10.67 & 7.27 \\
\hline 1998 & 2 & 15.67 & -13.67 & 11.93 \\
\hline 2010 & 7 & 15.67 & -8.67 & 4.8 \\
\hline Sum & 235 & & & 43.74 \\
\hline
\end{tabular}

which were obtained the Liaohe River and the second Songhua River most likely flooded in 2013. Indeed, in 2013 in the upper reaches of the Hun River and the Liaohe River a flood return period of over 50 years occurred. In the upper reaches of the Second Songhua River, a flood return period of over 20 years occurred. This verified the reliability of the forecasting methods.

As seen in Table 8, 2017 ranked second in the ternary commensurability calculation, fourth in the quinary commensurability calculation, and second in the septenary commensurability calculation. The specific quinary commensurability formula is listed in the table below. The locations of flooding were the second Songhua River or Liaohe River. Therefore, we predicted that floods in the second Songhua River or Liaohe River in northeastern China would occur in 2017.

\section{Commensurability Unit and Ordered Network Structure Chart}

\section{Commensurability Unit Calculation}

The commensurability unit (time scale) of the flooding years and frequency were obtained by deviation calculation with the data, taking the frequency above two as the commensurability unit, as shown in Table 10, wherein 21, 23, and 53 appeared four times, and 25, 28, 32,42 , and 51 appeared three times.

It can be seen that units $32,42,51$, and 53 may be derived by units $21,23,25$, and 28 :

$$
\begin{gathered}
25+28=53 \\
23+28=51 \\
21+21=42 \\
25+28-21=32
\end{gathered}
$$

So the basic commensurability unit is $21,23,25$ and 28.

\section{Ordered Network Structure Chart}

\begin{tabular}{|c|c|c|c|c|c|}
\hline \multicolumn{2}{|c|}{ Ternary Commensurability } & \multicolumn{2}{|c|}{ Quinary Commensurability } & \multicolumn{2}{|c|}{ Septenary Commensurability } \\
\hline Year & Number of Equations & Year & Number of Equations & Year & Number of Equations \\
\hline 2011 & 5 & 2011 & 177 & 2011 & 4,825 \\
\hline 2012 & 6 & 2012 & 195 & 2012 & 4,676 \\
\hline 2013 & 10 & 2013 & 234 & 2013 & 6,077 \\
\hline 2014 & 4 & 2014 & 162 & 2014 & 4,849 \\
\hline 2015 & 7 & 2015 & 215 & 2015 & 4,793 \\
\hline 2016 & 5 & 2016 & 163 & 2016 & 5,092 \\
\hline 2017 & 7 & 2017 & 207 & 2017 & 5,213 \\
\hline 2018 & 5 & 2018 & 233 & 2018 & 4,579 \\
\hline 2019 & 7 & 2019 & 195 & 2019 & 4,423 \\
\hline 2020 & 3 & 2020 & 128 & 2020 & 3,994 \\
\hline
\end{tabular}

We built the ordered network structure chart according to the commensurability unit, as shown in Figs 2 and 3.

Table 8. Results of the prediction model. 
Table 9. Ternary commensurability formulas of 2013 and 2017.

\begin{tabular}{|c|c|c|c|c|c|}
\hline Year & \multicolumn{3}{|c|}{ Ternary Commensurability Formula } & Frequency $\mathrm{x}$ & Probability $\%$ \\
\hline \multirow{4}{*}{2013} & $1888+1981-1856$ & $1960+2010-1957$ & $1981+1985-1953$ & \multirow{4}{*}{18} & \multirow{4}{*}{100} \\
\hline & $1909+1960-1856$ & $1962+1962-1911$ & $1985+1985-1957$ & & \\
\hline & $1960+1962-1909$ & $1962+1981-1930$ & $1998+2010-1995$ & & \\
\hline & $1960+1985-1932$ & & & & \\
\hline \multirow{3}{*}{2017} & $1888+1985-1856$ & $1960+2010-1953$ & $1981+1998-1962$ & \multirow{3}{*}{14} & \multirow{3}{*}{73} \\
\hline & $1911+1962-1856$ & $1962+1985-1930$ & $1985+1985-1953$ & & \\
\hline & $1930+1998-1911$ & & & & \\
\hline
\end{tabular}

Table 10. Commensurability unit and frequency.

\begin{tabular}{|c|c|c|c|c|c|}
\hline $\begin{array}{c}\text { Serial } \\
\text { Number }\end{array}$ & Unit & Frequency & $\begin{array}{c}\text { Serial } \\
\text { Number }\end{array}$ & Unit & Frequency \\
\hline 1 & 21 & 4 & 5 & 32 & 3 \\
\hline 2 & 23 & 4 & 6 & 42 & 3 \\
\hline 3 & 25 & 3 & 7 & 51 & 3 \\
\hline 4 & 28 & 3 & 8 & 53 & 4 \\
\hline
\end{tabular}

Fig. 2 is a two-dimensional ordered structure network. There are four very regular and orderly symmetrical rectangles. The commensurability units are 3a, 23a, 25a, $32 \mathrm{a}$, and $53 \mathrm{a}$, which are basic commensurability units or deduced by a basic commensurability unit.

Fig. 3 is a regular closed tetrahedron of threedimensional ordered structure. The frequency intervals are 3a, 23a, 25a, and 53a, which are basic commensurability units or deduced by a basic commensurability unit.

\section{Butterfly Structure Diagram}

We selected the period from 1930 to 2013 to make the butterfly structure symmetry analysis shown in Fig. 4. We

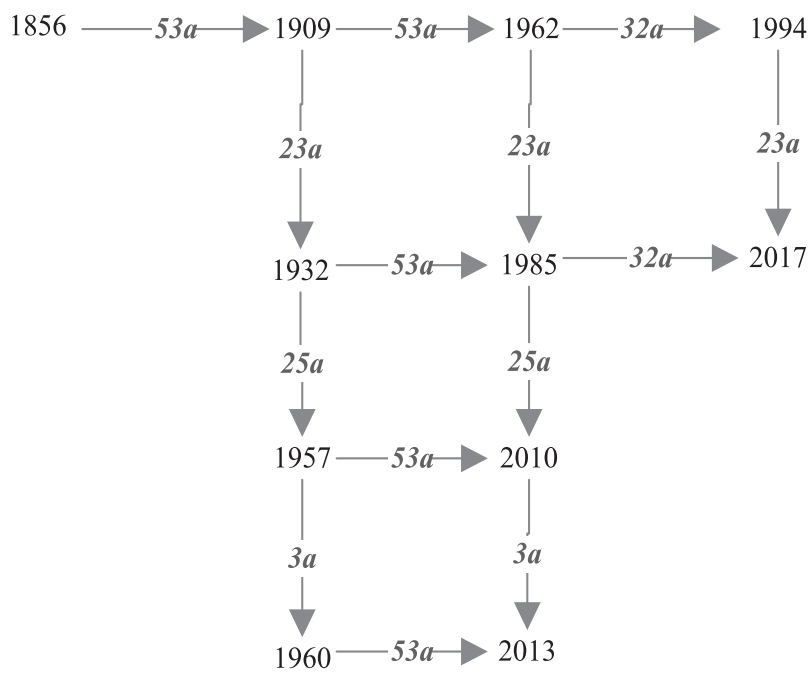

Fig. 2. Two-dimensional ordered structure network. set 1981 as the symmetric point, and the vertical line as the axis of symmetry. The number of groups achieved six, the symmetrical structure was very clear, and it reached the reference standard in Table 3. Fig. 4 reflects that the most significant units were 23a, 25a, 28a, 32a, 53a, and 55a. The most typical unit was a $32 \mathrm{a}$, which occurred four times, and 23a, 25a, 28a, and 53a each appeared three times. The predicted year 2017 participated in three groups (23a, 32a, and 55a), and the number of years involved in the prediction was 10 . The probability calculation of the event prediction was $\mathrm{T}=\mathrm{m} / \mathrm{n}=10 / 12=83 \%$, which meant there was an $83 \%$ probability that flooding would occur in 2017.

\section{Point Forecast}

The Baishan, Fengman, Yunfeng, and Jingpohu reservoirs are large, incomplete or complete, multiyear regulating storage reservoirs. Therefore, the peak series data of the reservoirs did not conform to the actual situation of flooding. According to the actual situation of each reservoir data, this paper used the maximum threeday inflow of Baishan Reservoir, the maximum daily inflow of Fengman Reservoir, and the average flow rates in the main flood season of Yunfeng and Jingpohu

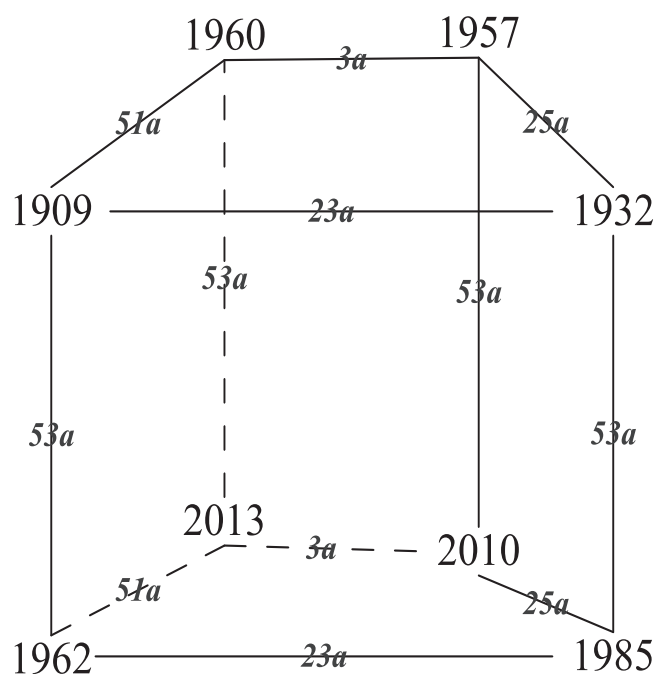

Fig. 3. Three-dimensional ordered structure network. 


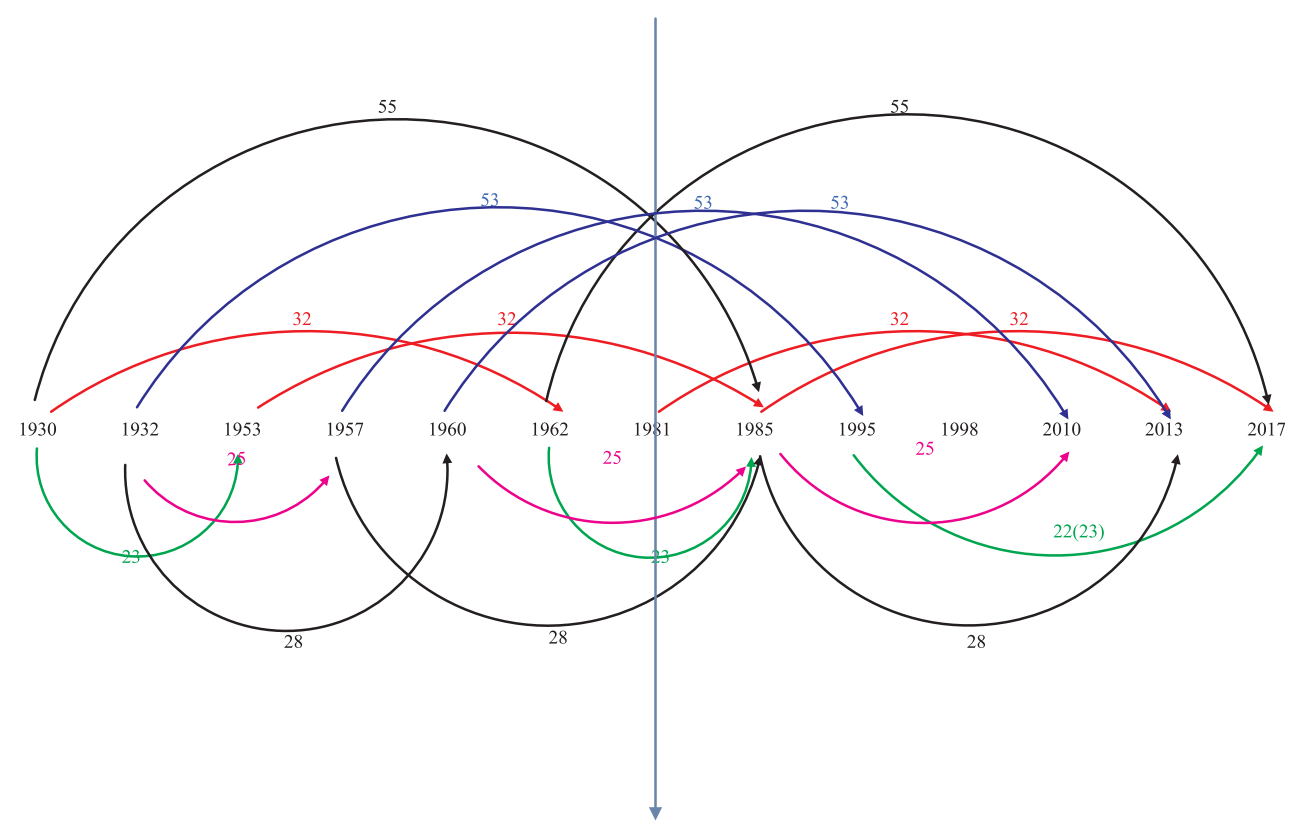

Fig. 4. Butterfly structure diagram.

reservoirs to forecast if the reservoirs would be wet or dry in a given year.

\section{Forecast Result of the Baishan Reservoir Commensurability Formula}

The study subject was the years whose three-day average discharge departed from the mean value more than 20\% in the Baishan Reservoir from 1933-2010.

Table 12 shows that the maximum of the actual frequency is 2017. The year 2020 may have the greatest probability for a flood. Baishan Reservoir should have abundant water resources in 2017 and 2020 .

Table 11. Series sample data of Baishan Reservoir. (Time was recorded on the first day of the maximum three days)

\begin{tabular}{|c|c|c|}
\hline $\begin{array}{c}\text { Serial } \\
\text { Number }\end{array}$ & $\begin{array}{c}\text { Time of } \\
\text { Sample }\end{array}$ & $\begin{array}{c}\text { Maximum Average Flow } \\
\text { in Three Days }\left(\mathrm{m}^{3} / \mathrm{s}\right)\end{array}$ \\
\hline 1 & $1937 / 8 / 6$ & 3,441 \\
\hline 2 & $1943 / 8 / 29$ & 4,514 \\
\hline 3 & $1953 / 8 / 21$ & 3,684 \\
\hline 4 & $1957 / 8 / 22$ & 4,630 \\
\hline 5 & $1960 / 8 / 24$ & 5,594 \\
\hline 6 & $1975 / 7 / 31$ & 3,819 \\
\hline 7 & $1982 / 8 / 28$ & 4,259 \\
\hline 8 & $1986 / 8 / 29$ & 4,198 \\
\hline 9 & $1994 / 7 / 9$ & 3,117 \\
\hline 10 & $1995 / 7 / 29$ & 5,752 \\
\hline 11 & $2010 / 7 / 28$ & 6,265 \\
\hline
\end{tabular}

\section{Forecast Result of the Fengman Reservoir Commensurability Formula}

The study subject was the maximum daily inflow of Fengman Reservoir from 1856-2014. We took the years whose departure from the mean value was greater than $20 \%$, as shown in Table 13 .

Table 14 shows that the maximum of the actual frequency and the greatest probability year is 2017, and that inflow should be extremely abundant in 2017 .

\section{Forecast Results of the Yunfeng Reservoir Commensurability Formula}

The study subject was the average flow rate of the main flood season of Yunfeng Reservoir from 1927-2010. We took the years in which inflow was beyond the average $20 \%$ of the average flow rate in the main flood season (see Table 15).

The ternary commensurability model and the results (shown in Table 16) showed that there was no particularly significant year, indicating that the Yalu River would not be wet in nearly five years.

\section{Forecast Result of the Jingpohu Reservoir Commensurability Formula}

The study subject was the average flow rate in the main flood season of Jingpohu Reservoir from 1927-2010. From the top down, we took years in which the inflow was beyond the average $20 \%$ of the average flow rate in the main flood season (see Table 17).

The results showed that the maximum of the actual frequency and the greatest probability year was 2017 , with a $92 \%$ chance of being wet. Because the Jingpohu Reservoir is near the Second Songhua River Basin, 
Table 12. Ternary commensurability formula, frequency, and probability of Baishan Reservoir.

\begin{tabular}{|c|c|c|c|c|c|}
\hline Year & \multicolumn{3}{|c|}{ Ternary Commensurability Formula } & Frequency $\mathrm{x}$ & Probability $\%$ \\
\hline 2016 & $1943+2010-1937$ & $1975+1994-1953$ & $1982+1994-1960$ & 6 & 73 \\
\hline \multirow{2}{*}{2017} & $1960+1994-1937$ & $1975+1995-1953$ & \multirow{2}{*}{$1982+2010-1975$} & \multirow{2}{*}{10} & \multirow{2}{*}{73} \\
\hline & $1960+2010-1953$ & $1982+1995-1960$ & & & \\
\hline 2018 & $1960+1995-1937$ & $1975+1986-1943$ & $1994+2010-1986$ & 6 & 73 \\
\hline 2019 & $1982+1994-1957$ & $1986+1986-1953$ & $1995+2010-1986$ & 5 & 64 \\
\hline \multirow{2}{*}{2020} & $1953+2010-1943$ & \multirow{2}{*}{$1982+1995-1957$} & \multirow{2}{*}{$1986+1994-1960$} & \multirow{2}{*}{8} & \multirow{2}{*}{100} \\
\hline & $1975+1982-1937$ & & & & \\
\hline
\end{tabular}

Table 13. Series sample data of Fengman Reservoir.

\begin{tabular}{|c|c|c|}
\hline $\begin{array}{c}\text { Serial } \\
\text { Number }\end{array}$ & $\begin{array}{c}\text { Time of } \\
\text { Sample }\end{array}$ & $\begin{array}{c}\text { Maximum Daily Average } \\
\text { Inflow }\left(\mathrm{m}^{3} / \mathrm{s}\right)\end{array}$ \\
\hline 1 & 1856 & 15,300 \\
\hline 2 & $1909 / 7 / 24$ & 12,000 \\
\hline 3 & $1923 / 8 / 14$ & 10,500 \\
\hline 4 & $1939 / 9 / 8$ & 7,180 \\
\hline 5 & $1951 / 8 / 25$ & 10,367 \\
\hline 6 & $1953 / 8 / 20$ & 15,610 \\
\hline 7 & $1957 / 8 / 22$ & 14,450 \\
\hline 8 & $1960 / 8 / 24$ & 12,751 \\
\hline 9 & $1964 / 8 / 14$ & 8,215 \\
\hline 10 & $1975 / 8 / 1$ & 8,135 \\
\hline 11 & $1991 / 7 / 30$ & 8,984 \\
\hline 12 & $1995 / 7 / 31$ & 11,978 \\
\hline 13 & $2010 / 7 / 28$ & 10,543 \\
\hline 14 & $2013 / 8 / 16$ & 13,251 \\
\hline
\end{tabular}

the forecast result of the Jingpohu Reservoir in the Mudanjiang watershed indirectly demonstrated that the runoff of the second Songhua River Basin would be extremely abundant.

In summary, the runoff of the Second Songhua River in northeastern China in 2017 would be extremely wet, and flooding may occur.

\section{Conclusions}

Commensurability was first found in astronomy and was later extended to forecast natural disasters. It has recently been applied to seismology research. Hydrological forecasting needs further research and discussion. This paper adopted ternary, quinary, and septenary commensurability prediction models to forecast floods in northeastern China. The expansion and development of commensurability were corroborated with an ordered network structure chart and butterfly structure diagram, and we could further clarify the disaster year.

We found that the original disaster years had a very strong degree of commensurability by chi-square test, indicating that commensurability was non-accidental.

Table 14. Ternary commensurability formula, frequency, and probability of Fengman Reservoir.

\begin{tabular}{|c|c|c|c|c|c|}
\hline Year & \multicolumn{3}{|c|}{ Ternary Commensurability Formula } & Frequency $\mathrm{x}$ & Probability $\%$ \\
\hline \multirow{2}{*}{2016} & $1957+2010-1951$ & $1960+2013-1957$ & 1964+1991-1939 & \multirow{2}{*}{11} & \multirow{2}{*}{79} \\
\hline & $1960+1995-1939$ & $1964+1975-1923$ & $2013+2013-2010$ & & \\
\hline \multirow{3}{*}{2017} & $1909+1964-1856$ & $1960+2010-1953$ & $1975+1995-1953$ & \multirow{3}{*}{16} & \multirow{3}{*}{86} \\
\hline & $1951+1975-1909$ & $1964+2010-1957$ & $1995+2013-1991$ & & \\
\hline & $1957+2013-1953$ & $1964+2013-1960$ & & & \\
\hline 2018 & $1951+1923-1856$ & $1991+1991-1964$ & & 3 & 36 \\
\hline \multirow{2}{*}{2019} & $1951+1991-1923$ & $1957+2013-1951$ & 1964+1964-1909 & \multirow{2}{*}{12} & \multirow{2}{*}{86} \\
\hline & $1953+1975-1909$ & $1960+2010-1951$ & $1975+1995-1951$ & & \\
\hline \multirow{2}{*}{2020} & $1923+1953-1856$ & \multirow{2}{*}{$1964+1995-1939$} & \multirow{2}{*}{$1964+2013-1957$} & \multirow{2}{*}{8} & \multirow{2}{*}{71} \\
\hline & $1960+2013-1953$ & & & & \\
\hline
\end{tabular}


Table 15. Series sample data of Yunfeng Reservoir.

\begin{tabular}{|c|c|c|}
\hline $\begin{array}{c}\text { Serial } \\
\text { Number }\end{array}$ & $\begin{array}{c}\text { Time of } \\
\text { Sample }\end{array}$ & $\begin{array}{c}\text { Average Flow Rate in Main } \\
\text { Flood Season }\left(\mathrm{m}^{3} / \mathrm{s}\right)\end{array}$ \\
\hline 1 & 1929 & 829 \\
\hline 2 & 1934 & 987 \\
\hline 3 & 1935 & 950 \\
\hline 4 & 1942 & 1,240 \\
\hline 5 & 1953 & 1,165 \\
\hline 6 & 1960 & 1,058 \\
\hline 7 & 1963 & 883 \\
\hline 8 & 1966 & 817 \\
\hline 9 & 1972 & 897 \\
\hline 10 & 1986 & 963 \\
\hline 11 & 1995 & 1,390 \\
\hline 12 & 2004 & 915 \\
\hline 13 & 2005 & 854 \\
\hline 14 & 2010 & 1,019 \\
\hline
\end{tabular}

After mutual authentication of ternary, quinary, and septenary commensurability calculations, the signal of 2013 ranked first and verified the inevitability of the flood in northeastern China in 2013. The signal strength of 2017 followed, and the location of flooding years participated was the second Songhua River or Liaohe River. Therefore, we predicted that flooding would occur in the second Songhua River or Liaohe River in northeastern China in 2017. Commensurability units were obtained by deviation
Table 17. Series sample data of Jingpohu Reservoir.

\begin{tabular}{|c|c|c|}
\hline $\begin{array}{c}\text { Serial } \\
\text { Number }\end{array}$ & $\begin{array}{c}\text { Time of } \\
\text { Sample }\end{array}$ & $\begin{array}{c}\text { Average Flow Rate in Main Flood } \\
\text { Season }\left(\mathrm{m}^{3} / \mathrm{s}\right)\end{array}$ \\
\hline 1 & 1953 & 360.5 \\
\hline 2 & 1956 & 599.5 \\
\hline 3 & 1957 & 386.55 \\
\hline 4 & 1960 & 434 \\
\hline 5 & 1964 & 524.5 \\
\hline 6 & 1971 & 396 \\
\hline 7 & 1972 & 365.5 \\
\hline 8 & 1983 & 361.5 \\
\hline 9 & 1985 & 400.5 \\
\hline 10 & 1986 & 495 \\
\hline 11 & 1987 & 625 \\
\hline 12 & 1991 & 604 \\
\hline 13 & 2002 & 413 \\
\hline
\end{tabular}

calculation, and the basic commensurability units were 21a, 23a, 25a, and 28a. The ordered network structure chart and butterfly structure diagram were made from commensurability unit information. The graphics were very neat and orderly and showed perfect symmetry, indicating the great possibility of flooding in the region in 2017 intuitively.

In this paper, we not only forecast the whole region on a large scale, but also combined small-scale points to accomplish flood forecasting. We selected the Baishan,

Table 16. Ternary commensurability formula, frequency, and probability of Yunfeng Reservoir

\begin{tabular}{|c|c|c|c|c|c|}
\hline Year Prediction & Ter & Commensurability $\mathrm{I}$ & ula & Frequency $\mathrm{x}$ & Probability \% \\
\hline \multirow{3}{*}{2016} & $1935+2010-1929$ & $1966+2010-1960$ & $1972+2010-1966$ & \multirow{3}{*}{15} & \multirow{3}{*}{79} \\
\hline & $1953+2005-1942$ & $1972+1986-1942$ & $2010+2010-2004$ & & \\
\hline & $1963+1995-1942$ & $1972+2004-1960$ & & & \\
\hline \multirow{3}{*}{2017} & $1942+2004-1929$ & $1960+2010-1953$ & $1966+2004-1953$ & \multirow{3}{*}{14} & \multirow{3}{*}{79} \\
\hline & $1942+2010-1935$ & $1966+1986-1935$ & $1972+2005-1960$ & & \\
\hline & $1960+1986-1929$ & & & & \\
\hline \multirow{3}{*}{2018} & $1942+2005-1929$ & $1966+2005-1953$ & $1986+2004-1972$ & \multirow{3}{*}{16} & \multirow{3}{*}{86} \\
\hline & $1942+2010-1934$ & 1986+1966-1934 & $1995+1995-1972$ & & \\
\hline & $1966+1986-1934$ & $1986+1995-1963$ & & & \\
\hline \multirow{3}{*}{2019} & $1953+1995-1929$ & $1986+1986-1953$ & $1995+2010-1986$ & \multirow{3}{*}{13} & \multirow{3}{*}{79} \\
\hline & $1966+1995-1942$ & $1986+2005-1972$ & $2004+2010-1995$ & & \\
\hline & $1972+2010-1963$ & & & & \\
\hline \multirow{2}{*}{2020} & $1960+1995-1935$ & \multirow{2}{*}{$1963+2010-1953$} & \multirow{2}{*}{$2005+2010-1995$} & \multirow{2}{*}{8} & \multirow{2}{*}{64} \\
\hline & $1963+1986-1929$ & & & & \\
\hline
\end{tabular}


Table 18. Ternary commensurability formula, frequency, and probability of Jingpohu Reservoir.

\begin{tabular}{|c|c|c|c|c|c|}
\hline Year & \multicolumn{3}{|c|}{ Ternary Commensurability Formula } & Frequency $\mathrm{x}$ & Probability $\%$ \\
\hline \multirow{3}{*}{2016} & $1971+2002-1957$ & $1985+1991-1960$ & $1986+1987-1957$ & \multirow{3}{*}{15} & \multirow{3}{*}{92} \\
\hline & $1983+1986-1953$ & $1985+2002-1971$ & $1986+2002-1972$ & & \\
\hline & $1985+1987-1956$ & $1986+1986-1956$ & & & \\
\hline \multirow{4}{*}{2017} & $1971+2002-1956$ & $1985+1985-1953$ & $1987+1987-1957$ & \multirow{4}{*}{19} & \multirow{4}{*}{92} \\
\hline & $1972+2002-1957$ & $1986+1987-1956$ & $1987+2002-1972$ & & \\
\hline & $1983+1987-1953$ & $1986+1991-1960$ & $2002+2002-1987$ & & \\
\hline & $1983+1991-1957$ & $1986+2002-1971$ & & & \\
\hline \multirow{3}{*}{2018} & $1972+2002-1956$ & $1987+1987-1956$ & 1991+1991-1964 & \multirow{3}{*}{13} & \multirow{3}{*}{92} \\
\hline & $1983+1991-1956$ & $1987+1991-1960$ & $2002+2002-1986$ & & \\
\hline & $1985+1986-1953$ & $1987+2002-1971$ & & & \\
\hline \multirow{2}{*}{2019} & $1985+1987-1953$ & \multirow{2}{*}{$1986+1986-1953$} & \multirow{2}{*}{$2002+2002-1985$} & \multirow{2}{*}{6} & \multirow{2}{*}{54} \\
\hline & $1985+1991-1957$ & & & & \\
\hline \multirow{2}{*}{2020} & $1971+2002-1953$ & \multirow{2}{*}{$1986+1987-1953$} & \multirow{2}{*}{ 1986+1991-1957 } & \multirow{2}{*}{8} & \multirow{2}{*}{69} \\
\hline & $1985+1991-1956$ & & & & \\
\hline
\end{tabular}

Fengman, Yunfeng, and Jingpohu reservoirs at higher flood incidence regions in the east or south of northeastern China as the sample points. The forecast results of the Baishan and Fengman reservoirs in the second Songhua River and the Jingpohu Reservoir in the Mudanjiang River all showed that 2017 would be wet. Because the Jingpohu Reservoir is located near the second Songhua River Basin, it indirectly demonstrated that the runoff of the Second Songhua River Basin would be wet in 2017. By combining specific points with macroscopic surface prediction, we mutually demonstrated the reasonableness of forecasts from time and space.

Some of the floods and the peak series data considered in the study may be due to the operation of the reservoirs. In the point forecast, we used the maximum three-day inflow of the Baishan Reservoir, the maximum daily inflow of the Fengman Reservoir, and the average flow rates in the main flood season of the Yunfeng and Jingpohu reservoirs according to the actual situation of each reservoir data. In the whole northeastern China regional forecast we considered the peak flow for the prediction but did not mention about the duration of the flood. For the next stage we will consider the operation of the reservoirs.

The author of the study also found that in the ordered network structure chart and butterfly structure diagram, not every node confirmed that commensurability would be a disaster, whether false readings also need to be combined with other prediction methods, such as the movement of celestial objects and the El Nino phenomenon. According to astronomical research, 60 years is the synodic period of Saturn, Jupiter, and Mercury. At the same time, the Earth's rotation period is 60 years. For two simultaneous cycles, this synchronization can cause droughts, earthquakes, and other natural disasters. The floods in 1953 and 1957, pushed forward 60 years, corresponded to 2013 and 2017. 2013 was a fait accompli; therefore, the probability of flooding is very large in 2017.

The commensurability research method has its unique accuracy and reasonableness. The commensurability method is a research method of seeking difference. Its main operations are addition and subtraction, effectively saving the authenticity of the information. However, the differential and higher-order differential expression in other methods would be detrimental to the expressed information. The character of commensurability method would also ensure that the method may achieve better results in disaster prediction. The year point predicted uses commensurability only as a necessary condition; the false is inevitable, and disaster prediction also should be combined with other prediction methods.

\section{Acknowledgements}

Our research was supported by the State key Basic Research and DevelopmentPlan of China(2013CB036406) and the State key Laboratory of Simulation and Regulation of Water Cycle in River Basin Foundation (2016ZY08). Thanks are due to Wenlong Li (Fengman Hydropower Plant) for assistance.

\section{References}

1. AMIRI E. Forecasting daily river flows using nonlinear time series models. Journal of Hydrology, 527, 1054, 2015.

2. AHN KUK-HYUN, PALMER R. Regional flood frequency analysis using spatial proximity and basin characteristics: 
Quantile regression vs. parameter regression technique. Journal of Hydrology, 540, 515, 2016.

3. WENG WENBO Basis of Prediction Theory. Petroleum Industry Press, China, 45, 1984 [In Chinese].

4. DENG JULONG Grey Prediction and Decision. Huazhong university of science and technology press, China, 15, 1986 [In Chinese].

5. YAN JUNPING Major natural disasters in time and space symmetry research. Publishing CNS of shaanxi normal university,China, 1, 2013 [In Chinese].

6. MEN K.P. Commensurability for Drought and Flood in China with Applications to Prediction. China Disaster Reduction, 9 (2), 14, 1999 [In Chinese].

7. HU H., HAN Y. Prediction of the Hualian Earthquakes in Taiwan and an Extended Discussion on the Method of Commensurability. Applied Geophysics, 2 (3), 194, 2005.

8. LI H., WU Y., LI X. Mountain Commensurability effect and differences in storm floods between northern and southern sources of the Songhua River Basin. Journal of Mountain Science, 9 (3), 431, 2012.

9. JIN J., YIN S., YAN J. Symmetry and tendency judgment of $\mathrm{Ms} \geq 8.0$ strong earthquakes in Chile. Geodesy \& Geodynamics, 37 (1), 34, 2014.

10. HU NANA Temporal Evolution and Tendency Judgment of Drought and Flood in Three Provinces in Northeast China. Shaanxi Normal University, 3, 2013 [In Chinese].
11. QIAO FENGXUE Study on the characteristics of Heavy Rainfall in Northeast China and the Structure of Nortneast Vortex. Graduate University of the Chinese Academy of Sciences, 1, 2007 [In Chinese].

12. JIANG TAO Uncertainty Analysis and Recommendations of Flood Forecast in Fengman Reservoir. Water Resources \& Hydropower of Northeast China, 32 (12), 1, 2014 [In Chinese].

13. WANG GUOLI, LIANG GUOHUA, ZHU YONGYING, et al. Decision-Making Support System of Dynamic Operation on Yunfeng Reservoir Normal Elevation in Flood Season. South-to-North Water Transfers and Water Science \& Technology, 7 (1), 47, 2009 [In Chinese].

14. LI YANLONG Jingpohu Reservoir's Optimizing Dispatch and Supervision. North China Electric Power University (Beijing), 4, 2009 [In Chinese].

15. GENG XIN-XIN, LI HONG-YAN Application of Commensurability to Forecast the Flood and Draught Disasters in Nenjiang River Basin. Yellow River, 34 (5), 34, 2012 [In Chinese].

16. YAN JUN-PING, BAI JING, SU KUN-HUI, et al. Research on Symmetry and Tendency of Several Major Natural Disasters. Geogrephical Research, 30 (7), 1159, 2011 [In Chinese]. 